\title{
World Journal of Pediatric Surgery \\ Clinical and epidemiological features of tibial tubercle avulsion fracture in Chinese adolescents
}

Yueqiang Mo $\odot$, Dahui Wang

To cite: Mo Y, Wang D. Clinical and epidemiological features of tibial tubercle avulsion fracture in Chinese adolescents. World JnI Ped Surgery 2020;3:e000169. doi:10.1136/wjps-2020-000169

Received 5 June 2020 Revised 5 August 2020 Accepted 13 August 2020
Check for updates

(C) Author(s) (or their employer(s)) 2020. Re-use permitted under CC BY-NC. No commercial re-use. See rights and permissions. Published by BMJ.

Pediatric Orthopedics, Children's Hospital of Fudan University, Shanghai, China

Correspondence to Dr Dahui Wang; wangdahui@ fudan.edu.cn

\section{ABSTRACT}

Background Tibial tubercle avulsion fracture is rare in children. Accumulated knowledge on clinical and epidemiological features of this fracture is of practical significance for clinical colleagues to deal effectively with such fractures.

Methods Clinical and epidemiological parameters were reviewed retrospectively in 29 patients with tibial tubercle avulsion fracture that was treated in our hospital in the past 7 years.

Results Totally, 29 children with 30 tibial tubercle fractures were enrolled. They were all boys; the average age was $13.8(12-15)$ years, and the average Body Mass Index (BMI) was 26.4 (19.2-34.3). Statistically, 41.4\% of injuries occurred during jumping activities, and 1 (3.4\%), 12 (41.4\%) and 16 (55.2\%) patients were injured bilaterally, on the right and left sides, respectively. The patients were classified into type I (4), II (3), III (13) and IV (10) fractures. Two patients (three knees) with fractures of type IV received close reduction and cast immobilization for 6 weeks. One patient with fracture of type IV underwent close reduction and was fixed with two cannulated screws. The remaining 26 patients underwent open reduction and were fixed with two or three cannulated screws. The average follow-up time was 38 (14-98) months; no complication was noted. Twenty-seven patients had an excellent outcome.

Conclusion In Chinese adolescents, the tibial tubercle avulsion fracture predisposes to boys with higher body weight; jumping is the most common cause of injury; treatments show satisfactory outcome regardless of fracture types.

\section{INTRODUCTION}

The development of tibial tubercle experiences four stages: cartilaginous, apophyseal, epiphysial and bony. ${ }^{2}$ The proximal tibial epiphysis closes in a posterior to anterior direction and then distally to the tubercle apophysis; this makes the tuberosity vulnerable to fracture. ${ }^{1}$ Nevertheless, the tibial tubercle fracture is uncommon in children, accounting only for $0.4 \%-2.7 \%$ of pediatric fractures, and this fracture represents about less than $1 \%$ of all physeal injuries. ${ }^{3-5}$ Tibial tubercle fracture is most likely to occur in adolescents between the ages of 13 and 17
Key messages

What is already known about this subject?

- Tibial tubercle fracture is not common, and most of them occur in male adolescents during sporting activities.

- Tibial tubercle fractures mainly happen by a strong contraction of quadriceps when the knee is extending or by a violent passive knee flexion when the quadriceps is contracting

- Most of the tibial tubercle fracture needs an open reduction and has a satisfactory outcome.

What are the new findings?

- Basketball and running are the sports most often associated with tibial tubercle fracture.

- Overweight male adolescents are more likely to have this fracture.

- If a good reduction can be achieved, closed reduction and internal fixation may also be a good method.

How might it impact on clinical practice in the foreseeable future?

- Accumulated knowledge on clinical and epidemiological features of this fracture is of practical significance for clinical colleagues to diagnose effectively and to treat such fractures.

years. It is consistent with the time of the proximal tibial epiphysis development and fusion with tibial tubercle apophysis. ${ }^{6}$ The tibial tubercle avulsion fracture often occurs by a violent contraction of the patellar tendon.

As tibial tubercle avulsion fracture is rare, accumulated knowledge on clinical and epidemiological features of this fracture is of practical significance for clinical colleagues to deal effectively with such fractures. In this report, we reviewed all tibial tubercle avulsion fracture cases that were treated in our hospital in the past 7.5 years retrospectively.

\section{METHODS}

\section{Patients}

Recorded patients with the tibial tubercle avulsion fracture who were treated in our hospital from January 2012 to June 2019 
were studied. Patients with multiple fracture, open fracture, pathological fracture and systemic disorder were excluded. Totally, 29 patients with 30 fractures were included in this report. Patient's age, gender, weight, Body Mass Index (BMI), injury mechanism, involved side, clinical and radiographical examinations (X-ray and CT), treatment and complications, as well as outcomes, were reviewed. According to the modified Watson-Jones classification, fractures were classified as follows ${ }^{7}$ : type I, fracture distal to the junction of ossification center of tuberosity and proximal tibial epiphysis; type II, fracture extends into the junction of proximal tibial physis; type III, fracture extends to the joint through proximal tibial epiphysis; and type IV, fracture extends transversely through proximal tibial physis. The outcomes were evaluated and defined as poor (range of motion is limited to more than $20^{\circ}$, and symptomatic with daily or minimal activity), fair (range of motion is limited to less than $10^{\circ}$, and symptomatic with vigorous and full activity) and excellent (range of motion is normal, asymptomatic, or full activity). ${ }^{8}$

\section{Statistical analysis}

This report mainly uses descriptive statistics to present the clinical and epidemiological features of the tibial tubercle avulsion fracture in Chinese adolescents. Categorical variables are expressed as frequencies with percentages; continuous variables are expressed as mean with range.

\section{RESULTS}

\section{Summary of clinical and epidemiological features}

We identified a total of 29 patients with 30 tibial tubercle fractures in the past 7 years and 5 months. As shown in table 1 , all of the patients were boys with mean age of 13.8 years, body weight of $71.8 \mathrm{~kg}$ and BMI of $26.4 ; 12,16$ and 1 fractures occurred in right, left and both side(s); 8 $(27.6 \%)$ and $11(37.9 \%)$ injuries happened while playing basketball and running, respectively, and the most common injury mechanism was jumping during activities $(41.4 \%)$. According to the modified Watson-Jones classification, $4(13.3 \%), 3(10.0 \%), 13(43.3 \%)$ and 10 $(33.3 \%)$, fractures belong to types I, II, III and IV, respectively. The features of age, BMI and fracture type are shown in figures 1 and 2. Fractures of type III and IV take the largest proportion. More than half of the patients are obese. The normal weight status takes $30 \%$ of the fractures. We are unable to draw any conclusions about the relationship between different fracture types and BMI due to a paucity of patients. One patient with fracture of type I had associated patellar tendon avulsion; another with type III fracture had associated medial meniscus injury. No preoperative complications were recorded. One patient suffered from tissue infection after operation and was cured before discharge.

\begin{tabular}{|c|c|}
\hline Variable & Value \\
\hline Number of subjects, $n$ & 29 \\
\hline Male adolescents, n (\%) & $29(100)$ \\
\hline Age (y), mean (range) & $13.8(12-15)$ \\
\hline Weight (kg), mean (range) & $71.8(52-100)$ \\
\hline Number of fractures, $n(\%)$ & 30 \\
\hline Right side fractures & $12(41.4)$ \\
\hline Left side fractures & $16(55.2)$ \\
\hline Both side fractures & $1(3.4)$ \\
\hline \multicolumn{2}{|l|}{ Causes of injury, $n(\%)$} \\
\hline Basketball & $8(27.6)$ \\
\hline Running & $11(37.9)$ \\
\hline \multicolumn{2}{|l|}{ Watson-Jones classification, n (\%) } \\
\hline Type I & $4(13.3)$ \\
\hline Type II & $3(10.0)$ \\
\hline Type III & $13(43.3)$ \\
\hline Type IV & $10(33.3)$ \\
\hline \multicolumn{2}{|l|}{ Comorbidity, n (\%) } \\
\hline $\begin{array}{l}\text { Type I and associated patellar tendon } \\
\text { avulsion }\end{array}$ & $1(3.7)$ \\
\hline $\begin{array}{l}\text { Type III and associated medial } \\
\text { meniscus injury }\end{array}$ & $1(3.7)$ \\
\hline
\end{tabular}

\section{Treatment and outcome}

As shown in table 2, two patients (three fractures) with fractures of type IV received close reduction and cast immobilization for 6 weeks. One patient with fracture of type IV underwent close reduction and was fixed with two cannulated screws. The remaining 26 patients underwent open reduction and were fixed with two or three cannulated screws.

The cast was removed 6 weeks after surgery if the fracture demonstrated clinical and radiographical union. After cast removal, weight bearing was initiated under protection, as well as active flexion and extension of the knee and quadricep-strengthening exercises. The average follow-up time was 38 (14 to 98) months. No complications were noted until the last follow-up. Twenty-seven (93.1\%) patients had an excellent outcome; two patients $(6.9 \%)$

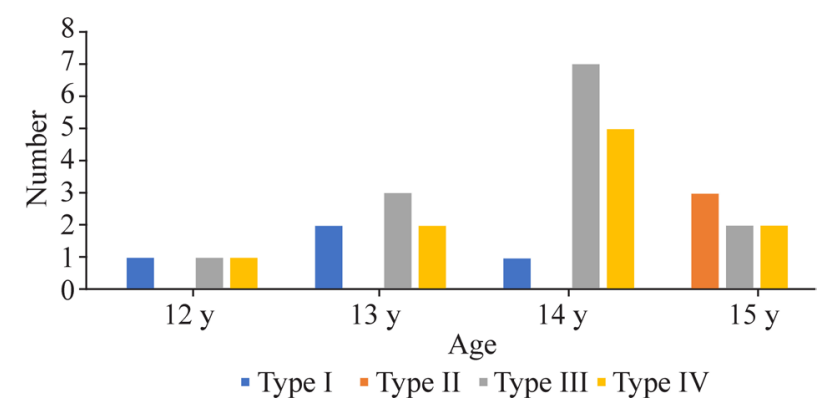

Figure 1 The number of four types of fractures in different age group. 


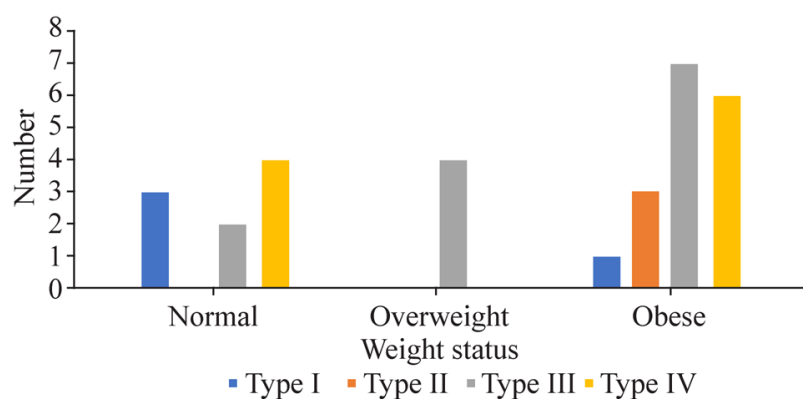

Figure 2 The number of four types of fractures in different weight status group.

were assessed as fair outcome. One of these patients had a little limp when running, and another patient had pain when flexing excessively at the last follow-up.

\section{DISCUSSION}

Tibial tubercle fracture is rare, but it always occurs in adolescent boys. The greater proportion of adolescent boys who participate in jumping activities may be a possible cause. ${ }^{1}$ As revealed by Ogden and Southwick, ${ }^{9}$ the correlation between tibial tubercle fracture and Osgood-Schlatter disease was not sure. Frey et al showed 3 of 19 children with pre-existing Osgood-Schlatter disease. ${ }^{10}$ However, no literature has reported the direct correlation between tibial tubercle fracture and Osgood-Schlatter disease. ${ }^{1}$ In our patients, there was no record of Osgood-Schlatter disease. The average age of our patients was 13.8 years, and all of them were boys; the most common mechanism of injury was related to jumping activities $(41.4 \%)$. These features are consistent with previous reports outside of China. ${ }^{10-15}$

Riccio et $a l^{16}$ reviewed 19 patients with tibial tubercle fracture. The BMI at the time of follow-up averages 28.8 (18.5-43.8). Shin et $a l^{17}$ stated that there was not enough evidence to prove that the high BMI would increase the likelihood of fractures. The average BMI in their series is 24.3 (16.0-31.1). The average BMI in our series is 26.4 (19.2-34.3), which means overweight. The relation between BMI and fracture is controversial.

\begin{tabular}{|c|c|c|}
\hline Variable & Number & Outcome \\
\hline \multicolumn{3}{|c|}{ Close reduction and cast immobilization $(n=2)$} \\
\hline Type IV & 1 & Fair \\
\hline \multicolumn{3}{|c|}{ Close reduction and fixed with two cannulated screws $(n=1)$} \\
\hline Type IV & 1 & Fair \\
\hline \multicolumn{3}{|c|}{$\begin{array}{l}\text { Open reduction and fixed with two or three cannulated screws } \\
(\mathrm{n}=27)\end{array}$} \\
\hline Type I & 4 & Excellent \\
\hline Type II & 3 & Excellent \\
\hline Type III & 13 & Excellent \\
\hline Type IV & 7 & Excellent \\
\hline
\end{tabular}

The mean follow-up period was 38 (14-98) months.
In children, obesity is thought to be a risk factor for the lower extremity fractures. ${ }^{18} 19$ Sabhaney $e t a l^{20}$ showed that increased risk of fractures among normal-weight children compared with underweight children has been proven to be proportional to BMI.

In part of the literature, left-sided injuries take preponderance. ${ }^{1421}$ As for a right-handed basketball player, the left leg is the push-off leg in a single-leg jump ${ }^{14}$; however, not all reports support this conclusion. Frey et al reported 8 left-sided and 10 right-sided injuries. ${ }^{6}$ In our 29 patients with 30 fractures, $55.2 \%(16 / 29)$ fractures occurred in left-sided injuries and $41.4 \%$ (12/29) injuries happened in right-sided injuries.

Sir Reginald Watson-Jones ${ }^{22}$ first classified the fracture into three types: type $I$ is a fracture through the tibial tubercle itself. Fractures of type II fail at the proximal tibial physis. Type III fractures extend into the joint through proximal tibial epiphysis. In 1980, Ogden et $a l^{7}$ made modifications to this classification; the previous fracture types were subdivided into group A (non-comminutive fractures) and B (comminutive fractures). In 1985, Ryu and Debenham ${ }^{23}$ added a fourth type of fracture, a fracture of the tibial epiphysis with posterior extension. In our patients, we found 4 fractures of type I, 3 fractures of type II, 13 fractures of type III and 10 fractures of type IV. Type III fractures were most frequently $(43.3 \%)$ seen in our patients, which was consistent with previous reports. ${ }^{1415}$ We were unable to draw any conclusions about the relationship between different fracture types, age and BMI due to a paucity of patients.

Patellar or quadriceps tendon avulsions and meniscal tears have been reported with tibial tubercle fracture; the total rates are as high as $10 \%-20 \% .^{13} 1424$ These were rarely observed in our patients. One patient in our study with type I fracture had an associated patellar tendon avulsion; another with type III fracture had an associated medial meniscus injury. However, this could be a false appearance caused by less using of more advanced medical imaging methods, such as MRI, to identify accompanying injuries like meniscus injury. Preoperative compartment syndrome was another associated injury, with an incidence of $4 \% .{ }^{14}$ None of our patients experienced this. One reason could be that we performed close or open reduction and fixation within a short time (an average of 2.3 days) after the injury, and this decompressed the compartment pressure.

Although treatments of tibial tubercle fractures result in satisfactory clinical outcomes regardless of fracture type,${ }^{14}$ outcomes measured by subjective validated surveys are not all satisfactory. ${ }^{16}$ In our study, two patients with fractures of type IV underwent close reduction and cast immobilization for 6 weeks; one patient with fracture of type IV underwent close reduction and was fixed with two cannulated screws; and the other 26 fractures underwent open reduction and were fixed with two or three cannulated screws. Among our patients, 27 subjects had an excellent outcome, and 2 had a fair outcome during 
14-98 months of follow-up; no complications were noted at the last follow-up.

\section{CONCLUSIONS}

Most tibial tubercle fractures occur in adolescent boys with overweight. Jumping is the most common activity of injury. Treatment ensures a good clinical outcome regardless of fracture type. A minor displaced fracture can be treated conservatively; the displaced fracture generally requires open reduction and internal fixation.

Contributors MYQ contributed to concept and design, acquisition of data, analysis and interpretation of data, and drafting of the article. WDH contributed to concept and design, analysis and interpretation of data, and revision of the article critically for important intellectual content. Both authors approved the final version of the manuscript to be published.

Funding The authors have not declared a specific grant for this research from any funding agency in the public, commercial or not-for-profit sectors.

Competing interests None declared.

Patient consent for publication Not required.

Ethics approval The review board of our hospital approved the study design. This study was conducted in accordance with the principles of the World Medical Association's Declaration of Helsinki.

Provenance and peer review Not commissioned; externally peer reviewed.

Data availability statement All data relevant to the study are included in the article or uploaded as supplementary information.

Open access This is an open access article distributed in accordance with the Creative Commons Attribution Non Commercial (CC BY-NC 4.0) license, which permits others to distribute, remix, adapt, build upon this work non-commercially, and license their derivative works on different terms, provided the original work is properly cited, appropriate credit is given, any changes made indicated, and the use is non-commercial. See: http://creativecommons.org/licenses/by-nc/4.0/.

ORCID iDs

Yueqiang Mo http://orcid.org/0000-0002-9096-5919

Dahui Wang http://orcid.org/0000-0002-3101-702X

\section{REFERENCES}

1 McKoy BE, Stanitski CL. Acute tibial tubercle avulsion fractures. Orthop Clin North Am 2003;34:397-403.

2 Ehrenborg G, Engfeldt B. The insertion of the ligamentum patellae on the tibial tuberosity. Some views in connection with the OsgoodSchlatter lesion. Acta Chir Scand 1961;121:491-9.
3 Bolesta MJ, Fitch RD. Tibial tubercle avulsions. J Pediatr Orthop 1986;6:186-92.

4 Ergün M, Tașkiran E, Ozgürbüz C. Simultaneous bilateral tibial tubercle avulsion fracture in a basketball player. Knee Surg Sports Traumatol Arthrosc 2003;11:163-6.

5 Hamilton SW, Gibson PH. Simultaneous bilateral avulsion fractures of the tibial tuberosity in adolescence: a case report and review of over 50 years of literature. Knee 2006;13:404-7.

6 Yousef MAA. Combined avulsion fracture of the tibial tubercle and patellar tendon rupture in pediatric population: case series and review of literature. Eur J Orthop Surg Traumatol 2018;28:317-23.

7 Ogden JA, Tross RB, Murphy MJ. Fractures of the tibial tuberosity in adolescents. J Bone Joint Surg Am 1980;62:205-15.

8 Abalo A, Akakpo-numado KG, Dossim A, et al. Avulsion fractures of the tibial tubercle. J Orthop Surg 2008;16:308-11.

9 Ogden JA, Southwick WO. Osgood-Schlatter's disease and tibia tuberosity development. Clin Orthop Relat Res 1976;116:180-9.

10 Frey S, Hosalkar H, Cameron DB, et al. Tibial tuberosity fractures in adolescents. J Child Orthop 2008;2:469-74.

11 Pandya NK, Edmonds EW, Roocroft JH, et al. Tibial tubercle fractures: complications, classification, and the need for intraarticular assessment. J Pediatr Orthop 2012;32:749-59.

12 Mubarak SJ, Kim JR, Edmonds EW, et al. Classification of proximal tibial fractures in children. J Child Orthop 2009;3:191-7.

13 Arkader A, Schur M, Refakis C, et al. Unicortical fixation is sufficient for surgical treatment of tibial tubercle avulsion fractures in children. J Pediatr Orthop 2019;39:e18-22.

14 Pretell-Mazzini J, Kelly DM, Sawyer JR, et al. Outcomes and complications of tibial tubercle fractures in pediatric patients: a systematic review of the literature. J Pediatr Orthop 2016;36:440-6.

15 Reuter S, Mellerowicz H. [Acute tibial tubercle avulsion fractures]. Orthopade 2016;45:226-32.

16 Riccio Al, Tulchin-Francis K, Hogue GD, et al. Functional outcomes following operative treatment of tibial tubercle fractures. J Pediatr Orthop 2019;39:e108-13.

17 Shin YW, Kim DW, Park KB. Tibial tubercle avulsion fracture according to different mechanisms of injury in adolescents: tibial tubercle avulsion fracture. Medicine 2019;98:e16700.

18 Kessler J, Koebnick C, Smith N, et al. Childhood obesity is associated with increased risk of most lower extremity fractures. Clin Orthop Relat Res 2013;471:1199-207.

19 Gilbert SR, MacLennan PA, Backstrom I, et al. Altered lower extremity fracture characteristics in obese pediatric trauma patients. J Orthop Trauma 2015;29:e12-7.

20 Sabhaney V, Boutis K, Yang G, et al. Bone fractures in children: is there an association with obesity? J Pediatr 2014;165:313-8.

21 Zrig M, Annabi H, Ammari T, et al. Acute tibial tubercle avulsion fractures in the sporting adolescent. Arch Orthop Trauma Surg 2008;128:1437-42.

22 Watson-Jones R. Injuries of the Knee. In: Fractures and joint injuries. 5 ed. Baltimore: Williams \& Wilkins, 1976: 1048-50.

23 Ryu RK, Debenham JO. An unusual avulsion fracture of the proximal tibial epiphysis. Case report and proposed addition to the WatsonJones classification. Clin Orthop Relat Res 1985;194:181-4.

24 Stepanovich MT, Slakey JB. Combined tibial tubercle avulsion fracture and patellar avulsion fracture: an unusual variant in an adolescent patient. Am J Orthop 2016;45:E31-4 